\title{
ESTS staging guidelines for non-small cell lung cancer: a good guide to best ever accuracy and high survival rate
}

\begin{abstract}
Akif Turna
Department of Thoracic Surgery, Istanbul University-Cerrahpasa Cerrahpasa School of Medicine, Fatih, İstanbul, Turkey Correspondence to: Akif Turna, MD, PhD, FETCS. Department of Thoracic Surgery, Istanbul University Cerrahpasa School of Medicine, Bilginler Sok. No.12, A Blok, Da:1, Sahrayicedid, Kadikoy, Istanbul 34734, Turkey. Email: aturna@istanbul.edu.tr.

Provenance: This is an invited article commissioned by the Section Editor Laura Chiara Guglielmetti (Cantonal Hospital Winterthur, Kantonsspital Winterthur, Switzerland).

Response to: Loo MK, Kim AW. Validating guideline concordant care in lung cancer also validates good surgical judgement and skill. J Thorac Dis 2018;10:1190-2.
\end{abstract}

Submitted Jun 17, 2018. Accepted for publication Jul 20, 2018.

doi: $10.21037 /$ jtd.2018.07.130

View this article at: http://dx.doi.org/10.21037/jtd.2018.07.130

Lung cancer causes most of the cancer-related deaths in men and women in the world (1). It is responsible for almost one-quarter $(23.6 \%)$ of all cancer deaths in men and $13.8 \%$ in women. Most of the patients with non-small cell lung cancer (NSCLC) can be diagnosed at an extensive stage with metastasis so they can not receive surgical therapy according to the published evidence (2). Surgical resection of NSCLC has been proven to be the primary and most effective treatment modality for patients with stage IA-IIIA (T3N1) $(3,4)$. Mediastinal lymph node metastasis (MLNM) $(\mathrm{N} 2$ or N3) is greatly important and it indicates patients whom the surgical resection is not beneficial (3-6). For this reason, accurate staging is crucial in choosing the patients who can benefit from the surgical resection as the best treatment and predicting the survival (3). A number of invasive and noninvasive staging methods can be used to evaluate MLNM before lung resection (7). Although positron emission tomography-computed tomography (PET-CT) can be used in mediastinal staging in patients with potentially operable NSCLC, the accuracy has been reported to be suboptimal (7) and preoperative mediastinal staging guidelines published by European Society of Thoracic Surgeons (ESTS) provides excellent road-map for patient selection and helps for unveiling N2 disease before. Since the patients with multiple N2 or contralateral (N3) MLNM can not benefit from surgical resection without preoperative chemo and/or radiotherapy (4-6), ESTS published a mediastinal staging guidelines for preoperative evaluation in 2007 and revised version was issued in $2014(7,8)$.
In our study, the validity of the ESTS revised preoperative mediastinal staging guidelines was validated (9). We analyzed the medical records of 571 patients with NSCLC who underwent surgical resection between 2004 and 2013 at our institution. According to latest guidelines (8), no mediastinal staging intervention [endobronchial ultrasonography guided transbronchial needle aspiration (EBUS-TBNA), mediastinoscopy] was performed in patients with PET/CT with no mediastinal metastasis, peripherally located small non-adenocarcinoma histology tumor $(<3 \mathrm{~cm})(8)$. All other patients underwent preoperative mostly videomediastinoscopy (VAM) or EBUS-TBNA preoperatively. A negative EBUS-TBNA was confirmed by mediastinoscopy. According to performed PET-CT, 240 patients $(42.0 \%)$ were cN0, whereas 56 $(9.8 \%)$ and $244(42.7 \%)$ and $31(5.4 \%)$ patients were evaluated to have $\mathrm{cN} 1, \mathrm{cN} 2$ and $\mathrm{cN} 3$ disease respectively. Two hundred patients (83.3\%) were found to have pN0 out of 240 patients with cN0 on PET-CT. Only the patients who had no mediastinal lymph node involvement after staging procedures underwent resectional surgery. Other patients with $\mathrm{N} 2$ disease were referred to neoadjuvant or definitive chemoradiation therapy. Three-hundred ninetyseven out of $571(69.5 \%)$ patients were treated surgically. After final histopathological examination, 293 patients out of 397 resected patients $(73.8 \%)$ were found to have no N2 disease (i.e., N1 or N0). Only 16 patients (4.0\%) who had no mediastinal lymph node after VAM or VAMLA $(n=266)$ were found to have N2 disease after final pathological 


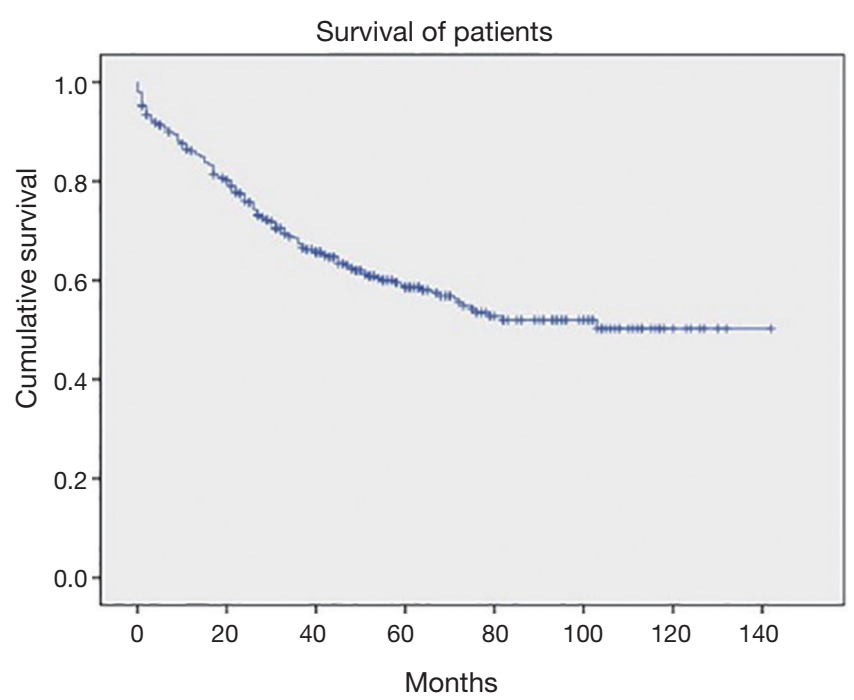

Figure 1 Survival of all patients who had resectional surgery.

evaluation. In patients whom the tumor is cT1N0 on PETCT, the negative predictive value was $95.6 \%$. On the other hand, 214 out of 275 patients (77.8\%) with cN2/3 disease were found to have $\mathrm{N} 2$ or $\mathrm{N} 3$ after VAM/VAMLA and/or resectional surgery.

With regard to importance of $\mathrm{cN} 1,24$ out of 56 patients with $\mathrm{cN} 1(42.9 \%)$ were disclosed to have N2 disease after VAM/VAMLA. Most of these positivities were disclosed at station \#8 and \#9 which were not totally accessible by mediastinoscopy. Negative predictive values of VAM/ VAMLA were calculated as $94.6 \%$ and $91.0 \%$ in patients with $\mathrm{cN} 0$ and $\mathrm{cN} 2$ respectively. When ESTS-guidelines are evaluated as a whole staging algorithm, the accuracy was 98.4\%. If we had not used ESTS guidelines for preoperative mediastinal staging 451 patients instead of 397 (additional 58 patients with $\mathrm{N} 2$ or $\mathrm{N} 3$ disease disclosed by the usage of guidelines) would have been operated. However, the guidelines were not perfectly accurate: out of 206 patients who were $\mathrm{cN} 0$ and having no MLNM after preoperative mediastinal staging, 11 (5.3\%) were found to have N2 disease after surgical resection in addition to lymph node dissection.

It is very important to note that, with implementation of ESTS guidelines, we observed very high survival rate in all operated individuals: the 5 -year survival rate of all patients was $65.5 \%$ (Figure 1) with a mean survival time was 97.1 months [95\% confidence interval (CI), 89-104 months].

In the study we wanted to emphasize four major findings: (I) accuracy, positive predictive value and negative predictive value of PET-CT as a mediastinal staging tool is too suboptimal and should not be trusted as a sole method; (II) implementation of ESTS guidelines with the usage of VAM as recommended instead of mediastinoscopy in patients with cN0 (non-peripheral T1), $\mathrm{cN} 2$ as well as $\mathrm{cN} 1$ patients is feasible and may increase the accuracy rate to a nearly statistically perfect level (i.e., 98.4\%); (III) there is no additional staging procedure for the patients with peripheral cT1N0 tumors; (IV) the strict compliance with ESTS staging guideline may lead to a very satisfiable survival which is 97.1 months of median survival (Figure 1).

It is plausible to claim that every appropriate staging procedures should be accomplished in order to disclose expected or unforeseen $\mathrm{N} 2$ disease before surgery, since upfront resection of NSCLC with N2/3 disease is futile (3-6). Moreover, latest improvements in oncology strikingly showed that, chemoradiotherapy with immunotherapy (anti-PDL1 therapy) my provide 23.2 months of median survival (10). For this reason, resection of these tumors may be deemed as unnecessary even harmful for the patients. As a result, current ESTS guidelines were proven to provide very high negative predictive value, accuracy and sensitivity in preoperative mediastinal staging. It also seems to be associated with satisfactory high survival in patients when applied.

\section{Acknowledgements}

None.

\section{Footnote}

Conflicts of Interest: The author has no conflicts of interest to declare.

\section{References}

1. Vallières E, Shepherd FA, Crowley J, et al. The IASLC Lung Cancer Staging Project: proposals regarding the relevance of TNM in the pathologic staging of small cell lung cancer in the forthcoming (seventh) edition of the TNM classification for lung cancer. J Thorac Oncol 2009;4:1049-59.

2. Howington JA, Blum MG, Chang AC, et al. Treatment of stage I and II non-small cell lung cancer: Diagnosis and management of lung cancer, 3rd ed: American College of Chest Physicians evidence-based clinical practice guidelines. Chest 2013;143:e278S-313S. 
3. Asamura H, Chansky K, Crowley J, et al. The International Association for the Study of Lung Cancer Lung Cancer Staging Project: Proposals for the Revision of the N Descriptors in the Forthcoming 8th Edition of the TNM Classification for Lung Cancer. J Thorac Oncol 2015;10:1675-84.

4. Pang Z, Yang Y, Ding N, et al. Optimal managements of stage III(N2) non-small cell lung cancer patients: a population-based survival analysis. J Thorac Dis 2017;9:4046-56.

5. Chen Y, Peng X, Zhou Y, et al. Comparing the benefits of chemoradiotherapy and chemotherapy for resectable stage III A/N2 non-small cell lung cancer: a meta-analysis. World J Surg Oncol 2018;16:8.

6. Albain KS, Swann RS, Rusch VW, et al. Radiotherapy plus chemotherapy with or without surgical resection for stage III non-small-cell lung cancer: a phase III randomised

Cite this article as: Turna A. ESTS staging guidelines for nonsmall cell lung cancer: a good guide to best ever accuracy and high survival rate. J Thorac Dis 2018;10(8):E661-E663. doi: $10.21037 /$ jtd.2018.07.130 controlled trial. Lancet 2009;374:379-86.

7. Silvestri GA, Gonzalez AV, Jantz MA, et al. Methods for staging non-small cell lung cancer: Diagnosis and management of lung cancer, 3rd ed: American College of Chest Physicians evidence-based clinical practice guidelines. Chest 2013;143:e211S-50S.

8. De Leyn P, Dooms C, Kuzdzal J, et al. Revised ESTS guidelines for preoperative mediastinal lymph node staging for non-small-cell lung cancer. Eur J Cardiothorac Surg 2014;45:787-98.

9. Turna A, Melek H, Kara HV, et al. Validity of the updated European Society of Thoracic Surgeons staging guideline in lung cancer patients. J Thorac Cardiovasc Surg 2018;155:789-95.

10. Antonia SJ, Villegas A, Daniel D, et al. Durvalumab after Chemoradiotherapy in Stage III Non-Small-Cell Lung Cancer. N Engl J Med 2017;377:1919-29. 